\title{
The creep clauses of BS7910
}

DOI:

10.1016/j.jpvp.2018.06.014

\section{Document Version}

Accepted author manuscript

Link to publication record in Manchester Research Explorer

\section{Citation for published version (APA):}

Ainsworth, R. (2018). The creep clauses of BS7910. International Journal of Pressure Vessels and Piping, 165. https://doi.org/10.1016/j.ijpvp.2018.06.014

\section{Published in:}

International Journal of Pressure Vessels and Piping

\section{Citing this paper}

Please note that where the full-text provided on Manchester Research Explorer is the Author Accepted Manuscript or Proof version this may differ from the final Published version. If citing, it is advised that you check and use the publisher's definitive version.

\section{General rights}

Copyright and moral rights for the publications made accessible in the Research Explorer are retained by the authors and/or other copyright owners and it is a condition of accessing publications that users recognise and abide by the legal requirements associated with these rights.

\section{Takedown policy}

If you believe that this document breaches copyright please refer to the University of Manchester's Takedown Procedures [http://man.ac.uk/04Y6Bo] or contact uml.scholarlycommunications@manchester.ac.uk providing relevant details, so we can investigate your claim.

\section{OPEN ACCESS}




\section{Accepted Manuscript}

The creep clauses of BS7910

R.A. Ainsworth

PII:

S0308-0161(18)30177-7

DOI:

10.1016/j.ijpvp.2018.06.014

Reference: IPVP 3728

To appear in: International Journal of Pressure Vessels and Piping

Received Date: 21 May 2018

Accepted Date: 22 June 2018

Please cite this article as: Ainsworth RA, The creep clauses of BS7910, International Journal of Pressure Vessels and Piping (2018), doi: 10.1016/j.jpvp.2018.06.014.

This is a PDF file of an unedited manuscript that has been accepted for publication. As a service to our customers we are providing this early version of the manuscript. The manuscript will undergo copyediting, typesetting, and review of the resulting proof before it is published in its final form. Please note that during the production process errors may be discovered which could affect the content, and all legal disclaimers that apply to the journal pertain. 


\title{
The Creep Clauses of BS7910
}

\author{
R A Ainsworth \\ The University of Manchester, Pariser Building, Sackville Street, Manchester \\ M13 9PL, UK.
}

\begin{abstract}
The creep parts of the BS7910 fitness-for-service procedure were first produced as PD6539 in 1994. Since then there have been significant developments in creep fracture mechanics. The current treatment of defects in the creep regime, as set out in BS7910, is described. The approach is straightforward to apply as illustrated by a worked example, adapted from that in an earlier version of the approach. The paper also discusses the use of BS7910 and future development needs.
\end{abstract}

Keywords: creep, fracture, fitness-for-service

\section{Introduction}

An assessment procedure for assessing defects in plant operating at temperatures sufficiently high for creep to be significant was first produced by the former Central Electricity Generating Board in 1987 [1]. The approach in [1] has subsequently been developed into the fracture parts of the R5 procedure [2], now maintained by EDF Energy. The approach in [1] was also used to develop the British Standards published document PD6539 [3] in 1994. This complemented the low temperature fracture and fatigue approaches which had been produced earlier as PD6493 [4]. The procedures of PD6493 and PD6539 were combined into BS7910 [5], as described in [6], a procedure that has been developed through a number of revisions into the current version [7]. The background to the creep fracture approach is described in detail in the book by Webster and Ainsworth [8].

Section 2 of this paper describes the creep procedure set out in Clause 9 of BS7910 [7]. The document also contains further information on materials data and treatment of weldments for creep assessment in Annex S and this is summarised in Section 3. To illustrate the application of the creep crack growth approach, Annex U of the 2005 version of BS7910 [9] contained a worked example. A simplified version of this example is presented in Section 4 of this paper. Finally, Section 5 of the paper discusses the industrial use of the BS7910 creep procedures and the further development needs.

\section{Clause 9 of BS7910}

Clause 9 of BS7910 [7] gives guidelines for assessing the significance of flaws in components that operate in the creep range. The clause presents procedures for describing creep or creep/fatigue failure by net section rupture and/or crack growth under both static and cyclic loading conditions. The calculations make use of limit analysis methods, continuum damage mechanics and fracture mechanics concepts.

As discussed in Section 1, the clause is based on the R5 procedures and earlier 
versions of British Standards documents. Information from the European FITNET approach [10] was also incorporated, but simplified where appropriate. Although Clause 9 was developed for assessing components made of ferritic and austenitic steels, the same principles are applicable to other metallic components provided relevant materials data and appropriate validation are obtained.

The procedures set out in Clause 9 assess whether a defect of a given size is likely to grow to an unacceptable size by creep or creep-fatigue mechanisms in a given service life under a given loading history. Before following the approach, it is first necessary to establish whether the component is operating in the creep region and guidance is given based on $\square$ the creep properties of all constituent materials in the component. Where crack propagation is possible and there is cyclic loading, guidance is also given on the need to treat creep-fatigue interaction. Here, the approach assuming both creep and cyclic loading are important is summarized.

The behaviour of a crack of initial size, $\mathrm{a}_{0}$, in a component subject to steady loading at elevated temperature is shown schematically in Figure 1 (Figure 27 of [7]). Following the initial loading, there is a crack initiation period, $t_{i}$, before crack propagation. Even if crack propagation does not occur, creep damage builds up ahead of the crack and creep rupture of the remaining material can occur at a time, $t_{C D}$. If crack propagation occurs, the rate of creep damage accumulation increases leading to a reduction in the continuum damage failure time, $\mathrm{t}_{\mathrm{CD}}$, as shown in Figure 1. This is described in terms of the reference stress, $\sigma_{\text {ref }}$, evaluated for the current crack size, a'. The crack growth conditions are shown diagrammatically in Figure 2 (Figure 28 of [7]) for a semielliptical defect of initial dimensions, $\mathrm{a}_{0}, \mathrm{c}_{0}$, with initiation of crack growth controlled by reaching a critical crack opening, $\delta_{i}$. Failure can be controlled by continuum damage or by crack growth to a crack size at which plastic collapse or short-term fracture governs and hence it is necessary to evaluate both mechanisms.

The calculations required to follow the creep part of BS7910 are set out in Clause 9.12. The first of these is to calculate the time to failure by continuum damage mechanisms. Both time-based and ductility-based approaches may be used. For loadings which are predominantly constant and primary, the stress is well known and it is appropriate to use stress/time-to-rupture relationships whereas for damage due to cyclic relaxation, the strain accumulated is limited in each cycle and ductility methods are appropriate. For predominately primary loading the time, $\mathrm{t}_{\mathrm{CD}}$, for creep damage to propagate through a structure and lead to failure is estimated as:

$$
\mathrm{t}_{\mathrm{CD}}=\mathrm{t}_{\mathrm{r}}\left[\sigma_{\text {ref }}(\mathrm{a})\right]
$$

where $\mathrm{t}_{\mathrm{r}}(\sigma)$ is the rupture time at stress, $\sigma$, from conventional stress/time-to-rupture data and the reference stress is calculated for the primary loads only for the current crack size, a, from

$$
\sigma_{\text {ref }}=\mathrm{P} \sigma_{\mathrm{y}} / \mathrm{P}_{\mathrm{L}}\left(\sigma_{\mathrm{y}}, \mathrm{a}\right)
$$

where $\mathrm{P}_{\mathrm{L}}$ is the value of $\mathrm{P}$ corresponding to plastic collapse assuming a yield strength, $\sigma_{\mathrm{y}}$. The effect of the flaw should be included in evaluating the plastic collapse load. 
For the purposes of initial calculation of the time for failure by continuum damage mechanics by equation (1) and for calculation of initiation time below, the relevant flaw size is that of the original defect; when crack growth is being considered, the relevant flaw size is the size of the original flaw plus the amount of crack growth.

For calculations of creep crack initiation time and to assess creep crack growth, the $\mathrm{C}^{*}$ parameter is evaluated according to

$$
\mathrm{C}^{*}=\sigma_{\text {ref }}(\mathrm{a}) \dot{\varepsilon}_{\mathrm{c}}\left[\sigma_{\text {ref }}(\mathrm{a}), \varepsilon_{\mathrm{c}}\right] \mathrm{R}^{\prime}
$$

where, $\dot{\varepsilon}_{\mathrm{c}}$ is the creep strain rate at the current reference stress and creep strain, $\varepsilon_{\mathrm{c}}$, accumulated under the reference stress history up to time t; normally, a strain hardening rule is used to define creep strain rates under increasing stress during the crack incubation and growth stages. The characteristic length, $\mathrm{R}^{\prime}$ is defined by

$$
\mathrm{R}^{\prime}=\left(\mathrm{K}^{\mathrm{p}} / \sigma_{\text {ref }}\right)^{2}
$$

where $\mathrm{K}^{\mathrm{p}}$ is the stress intensity factor due to primary load only. As both $\mathrm{K}^{\mathrm{p}}$ and the reference stress for primary loading are directly proportional to the loading $\mathrm{P}$, the value of $R^{\prime}$ is independent of the magnitude of $P$. However, $R^{\prime}$ does vary with crack size and, when crack growth is being considered, both $\mathrm{K}^{\mathrm{p}}$ and $\sigma_{\text {ref }}$ should be calculated for the defect size equal to the size of the original crack plus the amount of crack growth. The value of $\mathrm{R}^{\prime}$ is different at the surface and deepest points of a semi-elliptical surface defect due to differences in the values of $\mathrm{K}^{\mathrm{p}}$. For loadings more general than simple primary loading, BS7910 refers users to R5 [2] for methods for calculating $\mathrm{C}^{*}$.

The parameter $C^{*}$ is a steady state creep parameter and time is required for stress redistribution due to creep from the initial elastic state at the start of a creep dwell to steady state conditions. Steady state conditions are established for times in excess of a redistribution time, $\mathrm{t}_{\text {red }}$. When cyclic loading is insignificant, this may be expressed conveniently in terms of the reference stress for cases of primary load only as

$$
\varepsilon_{\mathrm{c}}\left[\sigma_{\text {ref }}(\mathrm{a}), \mathrm{t}_{\mathrm{red}}\right]=\sigma_{\text {ref }}(\mathrm{a}) / \mathrm{E}
$$

where $\varepsilon_{\mathrm{c}}\left[\sigma_{\text {ref }}(\mathrm{a}), \mathrm{t}\right]$ is the accumulated creep strain at the reference stress for time, $\mathrm{t}$, and crack size, a, from uniaxial creep data. For times less than the redistribution time, it may be necessary to calculate the transient crack tip parameter $\mathrm{C}(\mathrm{t})$ and BS7910 gives an interpolation formula for $\mathrm{C}(\mathrm{t})$ during the transition between initial elastic loading and steady state creep.

Having calculated $\mathrm{C}^{*}$ or $\mathrm{C}(\mathrm{t})$, the crack initiation time and instantaneous creep crack growth rate are evaluated from data. These may be obtained from suitable materials testing or from the information set out in Annex $\mathrm{S}$ as described in Section 3 below. 
Where there is cyclic loading, fatigue crack growth is evaluated from a Paris law and the effective stress intensity factor range, $\Delta \mathrm{K}_{\text {eff }}$. Creep influences the effective stress intensity factor range through the effect of creep relaxation on the mean stress in the cycle. This is treated through the R-ratio:

$$
\mathrm{R}=\mathrm{K}_{\min } / \mathrm{K}_{\max }
$$

where $\mathrm{K}_{\min }, \mathrm{K}_{\max }$ are the minimum and maximum values of the stress intensity factor in the cycle. Then, the effective stress intensity factor range is defined from

$$
\begin{array}{ll}
\Delta \mathrm{K}_{\text {eff }}=\mathrm{q}_{0}\left(\mathrm{~K}_{\text {max }}-\mathrm{K}_{\text {min }}\right) & \\
\mathrm{q}_{0}=1, & \mathrm{R} \geq 0 \\
\mathrm{q}_{0}=(1-0.5 \mathrm{R}) /(1-\mathrm{R}), & \mathrm{R}<0
\end{array}
$$

The parameter $\mathrm{q}_{0}$ defines the effective part of the cycle for which the crack is open. Further guidance on fatigue crack growth is provided in the fatigue clauses of BS7910. Fatigue crack growth and creep crack growth are simply summed to obtain the total crack growth. No interaction is assumed, although creep crack growth influences fatigue crack growth by increasing the crack size at which fatigue occurs, and vice versa.

\section{Annex S of BS7910}

Alternative crack initiation methods and the properties needed to derive initiation times are given in Annex $\mathrm{S}$ where available. When fatigue is insignificant and widespread creep is established, the initiation time, $t_{i}$, may be estimated from an estimate of $\mathrm{C}^{*}$ and data in the form

$$
\mathrm{t}_{\mathrm{i}}\left(\mathrm{C}^{*}\right)^{\beta}=\gamma
$$

where the constants $\beta, \gamma$ may be obtained from tests performed according to the standard ASTM E1457 [11] in which $C^{*}$ is estimated experimentally. In the absence of such test data, Annex $S$ provides alternative methods of estimating initiation time, including the use of creep crack growth data, which are described below.

Creep crack growth data are described in Annex $\mathrm{S}$ in the form

$$
\dot{\mathrm{a}}_{\mathrm{c}}=\mathrm{A}\left(\mathrm{C}^{*}\right)^{\mathrm{q}}
$$

Again, tests performed according to the standard ASTM E1457 [11], in which C* is estimated experimentally, may be used to obtain values for A and q. Alternatively, upper bound and mean values of $\mathrm{A}$ and $\mathrm{q}$ are tabulated in Annex $\mathrm{S}$ for a range of materials and temperatures. Moreover, Annex S provides a method for estimating A from uniaxial creep ductility data; when this estimate is used, $\mathrm{q}$ is set to $\mathrm{q}=0.85$.

Annex S also provides material creep deformation and rupture data for a range of materials and temperatures. The Annex also gives qualitative guidance on the treatment of defects in weldments and the types of cracking observed in weldments 
operating at high temperature. For detailed weld assessment, reference is made to the R5 procedure [2].

\section{Worked Example}

The example presented here is based on a problem and solution set out in BS7910:2005 Annex U [9]. That problem involved a variable loading history and secondary stresses but fatigue effects were found to be small. Therefore, the example is simplified here to consider only primary loading and a steady operating history. Modifications have also been made to present results using modern units.

\subsection{Geometry, loading and flaw}

The component considered is a plain pipe in a plant that operates for 28 days per month and for 11 months per year. The operating temperature is $575^{\circ} \mathrm{C}$ (note, in BS7910:2005 Annex U, the operating temperature was sometimes $550^{\circ} \mathrm{C}$ but here a single temperature is taken). The operating pressure is $40 \mathrm{bar}(=4 \mathrm{MPa})$, which leads to a membrane stress $\sigma_{\mathrm{m}}=60 \mathrm{MPa}$, but the plant may see short transients with a maximum pressure of 60 bar $(=6 \mathrm{MPa})$ and corresponding membrane stress of 90MPa. The plant started operation in April 1985 and a crack, as shown in Figure 3, was detected at the end of July 1990. The worked example solves the question of whether or not the plant can operate until the end of June 2005.

The flaw shown in Figure 3 was at the outer surface of the cylindrical vessel which had a diameter $\mathrm{D}=1050 \mathrm{~mm}$ and thickness $\mathrm{t}=35 \mathrm{~mm}$. The flaw was of irregular shape but following the rules in BS7910 is characterised as a semi-elliptical surface flaw with depth $\mathrm{a}=7 \mathrm{~mm}$ and semi-length $\mathrm{c}=20 \mathrm{~mm}$, i.e. $\mathrm{a} / \mathrm{c}=0.35$.

\subsection{Material properties}

The cylindrical vessel is made of Type 316 stainless steel with the tensile properties given in Table 1. The creep deformation and rupture properties of the material are described by

$$
\begin{aligned}
& \varepsilon^{c}=\sigma^{4} \exp \left(-\frac{19700}{T}\right)\left(4.010^{-3} t^{0.333}+5.2110^{-6} t\right) \\
& T\left(\log _{10} t_{r}+23\right)=2.686510^{4}-25.320 \sigma+1.974810^{-2} \sigma^{2}
\end{aligned}
$$

where $\varepsilon^{\mathrm{c}}$ is creep strain $\left(\mathrm{h}^{-1}\right), \mathrm{t}$ is time $(\mathrm{h}), \mathrm{T}$ is temperature $(\mathrm{K}), \sigma$ is stress $(\mathrm{MPa})$ and $t_{r}$ is lower bound rupture life (h). Creep crack growth properties are described in the form of eqn (9) by

$$
\dot{\mathrm{a}}_{\mathrm{c}}=36.5\left(\mathrm{C}^{*}\right)^{0.81}
$$

where crack growth rate is in $\mathrm{mm} / \mathrm{h}$ and $\mathrm{C}^{*}$ is in units of $\mathrm{MPa} \mathrm{m} / \mathrm{h}$.

\subsection{Initial fracture assessment}

Before a creep crack growth assessment is performed, a fracture assessment is 
performed according to BS7910 to ensure that the detected flaw is tolerable. This requires evaluation of the stress intensity factor and the reference stress, formulae for both of which are contained in BS7910. The stress intensity factor is

$$
\mathrm{K}=\sigma_{\mathrm{m}} \sqrt{\pi \mathrm{a}} \mathrm{M}_{\mathrm{m}}
$$

where $\sigma_{\mathrm{m}}$ is the membrane stress, and $\mathrm{M}_{\mathrm{m}}$ is obtained from Table M.8 in BS7910:2005 [9] by interpolation for $\mathrm{a} / \mathrm{c}=0.35, \mathrm{t} / \mathrm{R}<0.1$; this leads to $\mathrm{M}_{\mathrm{m}}^{\text {surface }}=0.67$, $\mathrm{M}_{\mathrm{m}}^{\text {deepest }}=1.017$ at the surface and deepest points of the flaw, respectively. The stress intensity factors for the fracture assessment are performed for the maximum operating pressure (membrane stress $=90 \mathrm{MPa}$ ) leading to

$$
\begin{aligned}
& \mathrm{K}^{\text {surface }}=90 \sqrt{\pi 0.007} 0.67=8.94 \mathrm{MPa} \sqrt{\mathrm{m}} \\
& \mathrm{K}^{\text {deepest }}=90 \sqrt{\pi 0.007} 1.017=13.6 \mathrm{MPa} \sqrt{\mathrm{m}}
\end{aligned}
$$

For the fracture assessment, these are normalised by the fracture toughness of 105 $\mathrm{MPa} \sqrt{\mathrm{m}}$ (Table 1) to give the values of the stress intensity factor ratio, $\mathrm{K}_{\mathrm{r}}$ :

$$
\begin{aligned}
& \mathrm{K}_{\mathrm{r}}^{\text {surface }}=8.94 / 105=0.085 \\
& \mathrm{~K}_{\mathrm{r}}^{\text {deepest }}=13.6 / 105=0.13
\end{aligned}
$$

Annex P of BS7910:2005 [9] gives a reference stress solution as

$$
\sigma_{\text {ref }}=1.2 \mathrm{M}_{\mathrm{s}} \sigma_{\mathrm{m}} \quad \mathrm{M}_{\mathrm{s}}=\frac{1-\left[\mathrm{a} /\left(\mathrm{tM}_{\mathrm{T}}\right)\right]}{1-\mathrm{a} / \mathrm{t}} \quad \mathrm{M}_{\mathrm{T}}=\sqrt{1+1.6\left[\mathrm{c}^{2} /\left(\mathrm{R}_{\mathrm{i}} \mathrm{t}\right)\right]}
$$

For $\mathrm{a}=7 \mathrm{~mm}, \mathrm{c}=20 \mathrm{~mm}$, the internal radius $\mathrm{R}_{\mathrm{i}}$ of $525 \mathrm{~mm}$ and $\mathrm{t}=35 \mathrm{~mm}$, this leads to

$$
\sigma_{\text {ref }}=108 \mathrm{MPa}
$$

and hence the limit load parameter, $\mathrm{L}_{\mathrm{r}}$, in BS7910 is

$$
\mathrm{L}_{\mathrm{r}}=\sigma_{\text {ref }} / \sigma_{\mathrm{y}}=108 / 112=0.97
$$

The cut-off on the failure assessment diagram used in the fracture part of BS7910 is defined from the properties in Table 1 as

$$
\mathrm{L}_{\mathrm{r}}^{\max }=0.5\left(\sigma_{\mathrm{y}}+\sigma_{\mathrm{uts}}\right) / \sigma_{\mathrm{y}}=2.2
$$

This information is sufficient for the initial fracture assessment and the assessment points for the surface and deepest points of the flaw are depicted on the failure assessment diagram in Figure 4. It is apparent that the points are well within the diagram so that the initial flaw is tolerable.

\subsection{Creep crack growth assessment}


As the flaw has been detected in service, it is assumed to be growing by creep and no allowance for an initiation time is made. The high temperature assessment then requires only a rupture assessment and an estimate of creep crack growth in service.

The rupture life assessment (analogous to plastic collapse) is based on the operating pressure, rather than the maximum pressure used in the fracture assessment, and the operating temperature of $575^{\circ} \mathrm{C}$. The reference stress for the initial flaw size has already been evaluated for the fracture assessment, at the maximum pressure, and this may be simply scaled to lead to the initial reference stress at the operating pressure as

$$
\sigma_{\text {ref }}=\frac{60}{90} 108=72.3 \mathrm{MPa}
$$

Using the rupture equation (10), this leads to an estimate of the rupture time of the component from eqn (1) as

$$
\mathrm{t}_{\mathrm{CD}}=4.310^{6} \mathrm{~h}
$$

If the crack is assumed to have been present from the start of life, this is well in excess of the operating hours to the end of June 2005, which are 150,000h. Thus creep rupture is not a problem if the crack does not grow.

To simplify the calculations, it is assumed that the future changes in crack size are insufficient to affect the calculations of $\mathrm{K}$ and reference stress (this transpires to be approximately correct and enables the worked example to be presented simply. However, it is straightforward to perform repeated calculations of the type illustrated here to allow for changes in these quantities as illustrated by the original example in BS7910:2005 and an example in [12]). With this approximation, it is possible to calculate an average creep strain rate for future operation from the difference in creep strain accumulated to end of life and that accumulated when the crack was detected. For the operating conditions of a membrane stress of $60 \mathrm{MPa}$ and temperature of $575^{\circ} \mathrm{C}$, the accumulated creep strain when the crack was detected at the end of July 1990 (i.e. after a period of operation of 40,000h) is obtained from eqn (10) using the reference stress of $72.3 \mathrm{MPa}$ as $0.077 \%$. The corresponding creep strain at the end of the required life $(150,000 \mathrm{~h})$ is $0.22 \%$. Therefore, the average creep strain rate at the reference stress is

$$
\dot{\varepsilon}_{\text {ref }}^{\mathrm{c}}=\frac{(0.22-0.077) \%}{(150,000-40,000) \mathrm{h}}=1.3210^{-8} \mathrm{~h}^{-1}
$$

The size parameter of eqn (4) is then

$$
\mathrm{R}^{\prime}=\mathrm{K}^{2} / \sigma_{\text {ref }}^{2} \quad \mathrm{R}^{\text {'surface }}=6.8 \mathrm{~mm} \quad \mathrm{R}^{\text {'deepest }}=15.7 \mathrm{~mm}
$$

Note, as both $\mathrm{K}$ and reference stress are proportional to pressure, this is independent of pressure and hence can be calculated directly from the solutions evaluated in Section 4.3. It is assumed that the component is in steady state creep from the start of life and then the estimates of $\mathrm{C}^{*}$ at the surface and deepest points follow from eqn (3) 
as

$$
\begin{aligned}
& \mathrm{C}_{\text {surface }}^{*}=72.3 \times 1.3210^{-8} \times 6.810^{-3}=6.510^{-9} \mathrm{MPamh}^{-1} \\
& \mathrm{C}_{\text {deepest }}^{*}=72.3 \times 1.3210^{-8} \times 15.710^{-3}=1.510^{-8} \mathrm{MPamh}^{-1}
\end{aligned}
$$

The creep crack growth rates then follow immediately from eqn (11) as

$$
\begin{aligned}
& \dot{\mathrm{a}}_{\mathrm{c}}^{\text {surface }}=36.5\left(6.510^{-9}\right)^{0.81}=8.510^{-6} \mathrm{~mm} / \mathrm{h} \\
& \dot{\mathrm{a}}_{\mathrm{c}}^{\text {deepest }}=36.5\left(1.510^{-8}\right)^{0.81}=1.710^{-5} \mathrm{~mm} / \mathrm{h}
\end{aligned}
$$

and the crack size at the required end of life is

$$
\begin{aligned}
& \mathrm{a}=7+1.710^{-5}(150,000-40,000)=8.8 \mathrm{~mm} \\
& \mathrm{c}=20+8.510^{-6}(150,000-40,000)=20.9 \mathrm{~mm}
\end{aligned}
$$

The high temperature assessment is completed by re-assessing the rupture life. Repeating the calculations of eqns $(21,22)$ based on the increased reference stress for the increased crack size leads to

$$
\sigma_{\text {ref }}=1.2 * 1.006 * 60=72.5 \mathrm{MPa}
$$

and

$$
\mathrm{t}_{\mathrm{CD}}=4.310^{6} \mathrm{~h}
$$

This is only a $1 \%$ reduction from that based on the initial reference stress and creep rupture is not an issue at end of life.

\subsection{Final fracture assessment}

The assessment is completed by repeating the calculations of Section 4.3 for the final flaw dimensions, including the creep crack growth. The results are summarized as follows:

$$
\begin{gathered}
\mathrm{M}_{\mathrm{m}}^{\text {surface }}=0.72, \quad \mathrm{M}_{\mathrm{m}}^{\text {deepest }}=0.98 \\
\mathrm{~K}^{\text {surface }}=90 \sqrt{\pi 0.0088} 0.72=10.8 \mathrm{MPa} \sqrt{\mathrm{m}}, \mathrm{K}_{\mathrm{r}}^{\text {surface }}=10.8 / 105=0.10 \\
\mathrm{~K}^{\text {deepest }}=90 \sqrt{\pi 0.0088} 0.98=14.7 \mathrm{MPa} \sqrt{\mathrm{m}}, \mathrm{K}_{\mathrm{r}}^{\text {deepest }}=14.7 / 105=0.14 \\
\mathrm{~L}_{\mathrm{r}}=\sigma_{\text {ref }} / \sigma_{\mathrm{y}}=(72.5 * 90 / 60) / 112=0.97
\end{gathered}
$$

The assessment points are shown on Figure 5, along with those for the initial flaw dimensions. There is little influence of creep crack growth on the fracture assessment and the flaw remains tolerable. Thus, it may be concluded that the component may continue operation until the required end of life.

\section{Industrial Use and Development Needs}




\subsection{Industrial Use}

There are a number of industries which operate plant at high temperatures for which the creep procedures of BS7910 are relevant. For example, coal-fired and gas-fired power generation and refining plant contain safety critical high temperature components for which demonstration of defect tolerance provides added assurance. In the UK, the boilers and some reactor internal components in the advanced gascooled reactors operate at temperatures in the creep range. These components have been operating for typically in excess of 30 years and creep assessments are important for demonstration of continued safe operation and for estimation of life extension. The UK nuclear industry uses the R5 procedure, rather than BS7910, but as noted in Section 1 the procedures have much in common.

\subsection{Development Needs}

While the creep clauses of BS7910 have been developed over many years, there is the potential for further development. Some areas where the methods or guidance could be improved are listed below.

Clause 10 of BS7910 addresses some effects of environment on engineering critical assessments. However, this does not address the interaction with creep. If the environment has a general effect on material properties through thermal ageing, for example, then this may be allowed for in the creep clauses by using material properties in the thermal aged condition. However, if the environment only affects material properties locally, say at a surface exposed to the environment, then the impact of environment on creep and or fatigue crack growth is more complex and further guidance could be given.

The creep procedures of Clause 9 of BS7910 are essentially deterministic. However, Annex K of BS7910 gives advice on performing probabilistic calculations, including those for creep rupture and creep crack growth. Given the large uncertainties in material properties at high temperature, deterministic assessments can be highly conservative if the most conservative assumptions are made at each stage of an assessment. Therefore, further guidance on probabilistic approaches would be valuable, particularly correlations between the different inputs in a creep assessment.

The procedures as described in this paper were initially developed for components subjected to primary loading. However, industrial components are also subjected to secondary stresses due to thermal transients and welding residual stresses. The procedures of BS7910 treat these additional stresses in a conservative manner but more accurate methods would be helpful for components where primary stresses are low and secondary stresses can be dominant.

The data presented in Annex S, particularly the creep crack growth data, are often based on short-term tests. Improved data for assessing creep and creep-fatigue crack incubation and growth at stresses, temperatures and timescales relevant to long-term plant operation would be invaluable.

As noted in Section 3, the guidance for assessing creep cracking in weldments is largely qualitative. Refinement of the methodology for assessing creep and creep- 
fatigue crack incubation and growth for both similar and dissimilar weldments would be a valuable addition to BS7910.

Extending validation of the BS7910 procedures, with emphasis on the aspects described in this section, should be performed in parallel with procedure and data development.

\section{Acknowledgments}

The paper draws heavily on BS7910 and the work of colleagues who have been involved in the creep working group leading to that documents is gratefully acknowledged.

\section{References}

1. R A Ainsworrth, G G Chell, M C Coleman, I W Goodall, D J Gooch, J R Haigh, S $\mathrm{T}$ Kimmins and G J Neate, CEGB assessment procedure for defects in plant operating in the creep range, Fatigue Fract Engng Mater Struct 10, 115-127 (1987).

2. R5 Issue 3, Revision 002, Assessment Procedure for the High Temperature Response of Structures, Issue 3, EDF Energy Generation, Gloucester, UK (2014).

3. PD6539, Methods for the assessment of the influence of crack growth on the significance of defects in components operating at high temperatures, British Standards institution, London (1994).

4. PD6493, Guidance on methods for assessing the acceptability of flaws in fusion welded structures, British Standards institution, London (1991).

5. BS7910:1999 (incorporating Amendment No.1), Guide on methods for assessing the acceptability of flaws in metallic structures, British Standards Institution, London (2000).

6. C S Wiesner, S J Maddox, W Xu, G A Webster, F M Burdekin, R M Andrews and J D Harrison, Engineering critical analyses to BS7910 - the UK guide on methods for assessing the acceptability of flaws in metallic structures, Int J Pres Ves Piping 77, 883-893 (2000).

7. BS7910:2013+A1, Guide on methods for assessing the acceptability of flaws in metallic structures, British Standards Institution, London (2015).

8. G A Webster and R A Ainsworth, High temperature component life assessment, Chapman \& Hall, London (1994).

9. BS7910:2005 (incorporating Amendment No.1), Guide to methods for assessing the acceptability of flaws in metallic structures, British Standards Institution, London (2007).

10. M Kocak, S Webster, J J Janosch, R A Ainsworth and R Koers, FITNET Fitnessfor-Service (FFS) - Procedure (Volume 1), GKSS Research Centre, Geesthacht, Germany (2008).

11. ASTM E1457-15, Standard test method for measurement of creep crack growth times in metals, ASTM International, West Conshohocken, PA, USA (2015).

12. R A Ainsworth and M C Coleman, Example of an application of an assessment 
procedure for defects in plant operating in the creep range, Fatigue Fract Engng Mater Struct 10, 129-140 (1987). 
Table 1: Tensile properties for worked example of Section 4

\begin{tabular}{|l|l|l|l|l|}
\hline Temperature & $\begin{array}{l}\text { Yield } \\
\text { stress }\end{array}$ & $\begin{array}{l}\text { Ultimate } \\
\text { stress }\end{array}$ & $\begin{array}{l}\text { Young's } \\
\text { modulus }\end{array}$ & $\begin{array}{l}\text { Fracture } \\
\text { toughness }\end{array}$ \\
\hline $575^{\circ} \mathrm{C}$ & $112 \mathrm{MPa}$ & $384 \mathrm{MPa}$ & $147 \mathrm{GPa}$ & $105 \mathrm{MPa} \sqrt{\mathrm{m}}$ \\
\hline
\end{tabular}




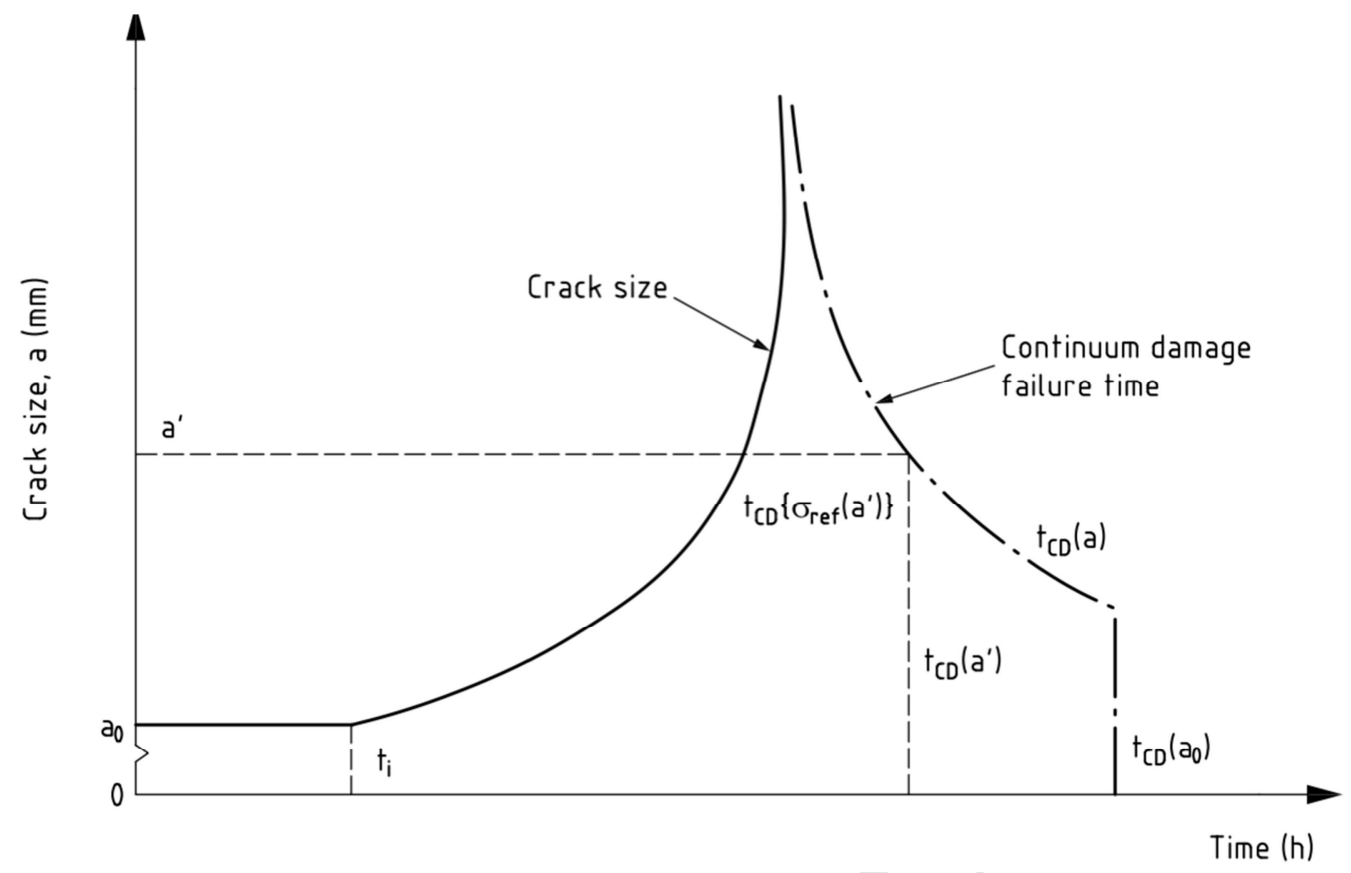

Figure 1. Schematic behaviour of a crack subjected to steady loading at elevated temperature (from [7]) 


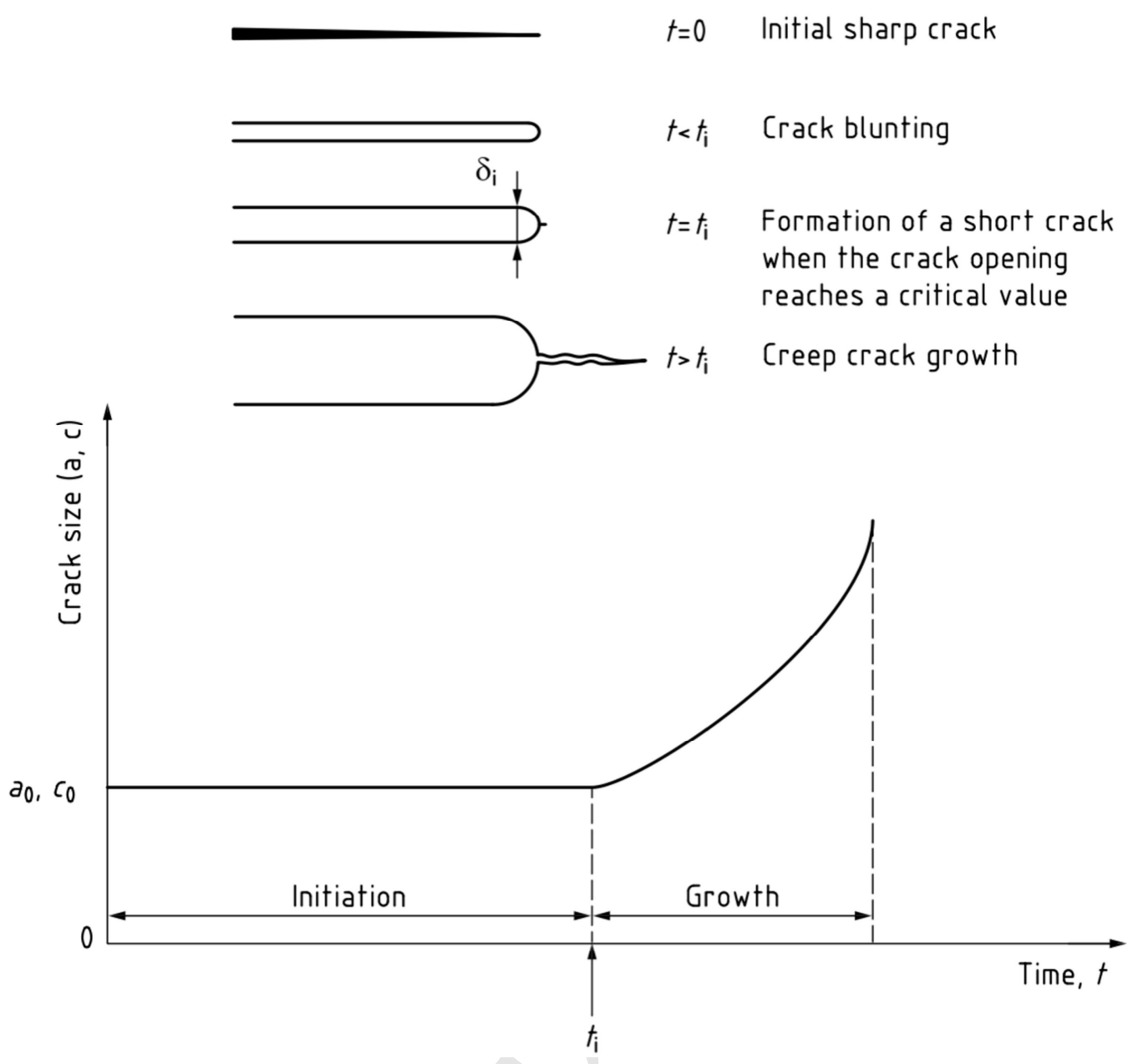

Figure 2. Schematic representation of crack propagation and failure conditions (from [7]).

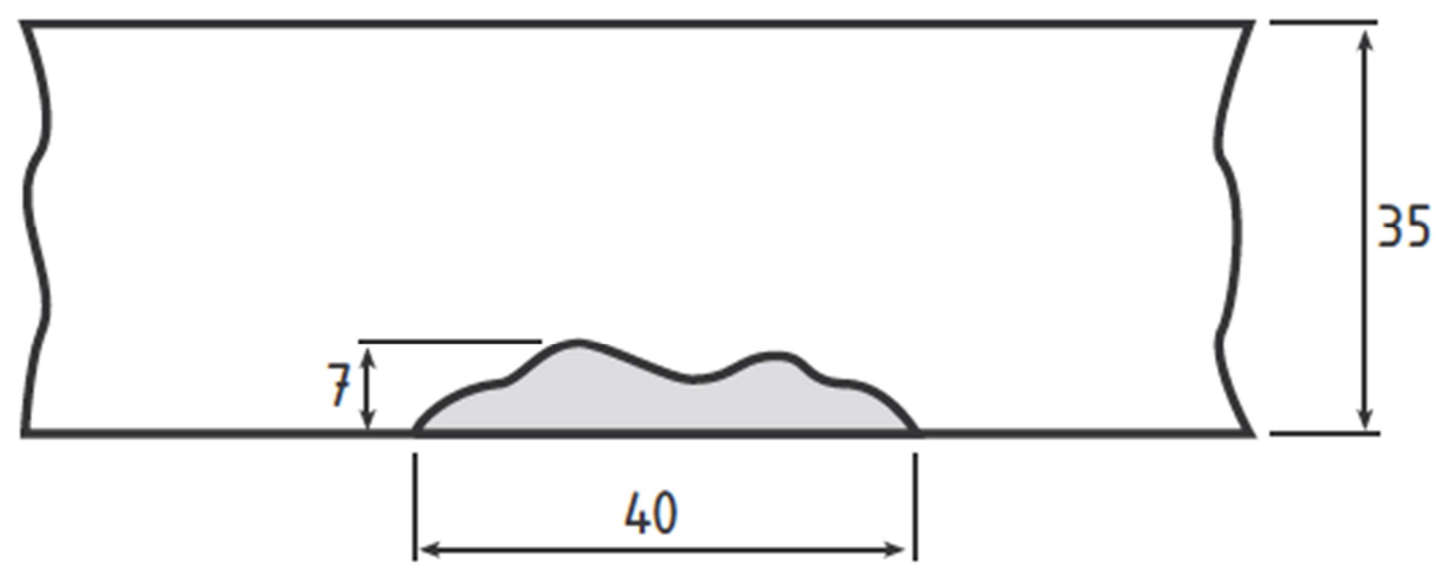

Figure 3. Flaw detected for worked example of Section 4. The flaw dimensions are in $\mathrm{mm}$ and the flaw is at the outer surface of a cylindrical vessel. 


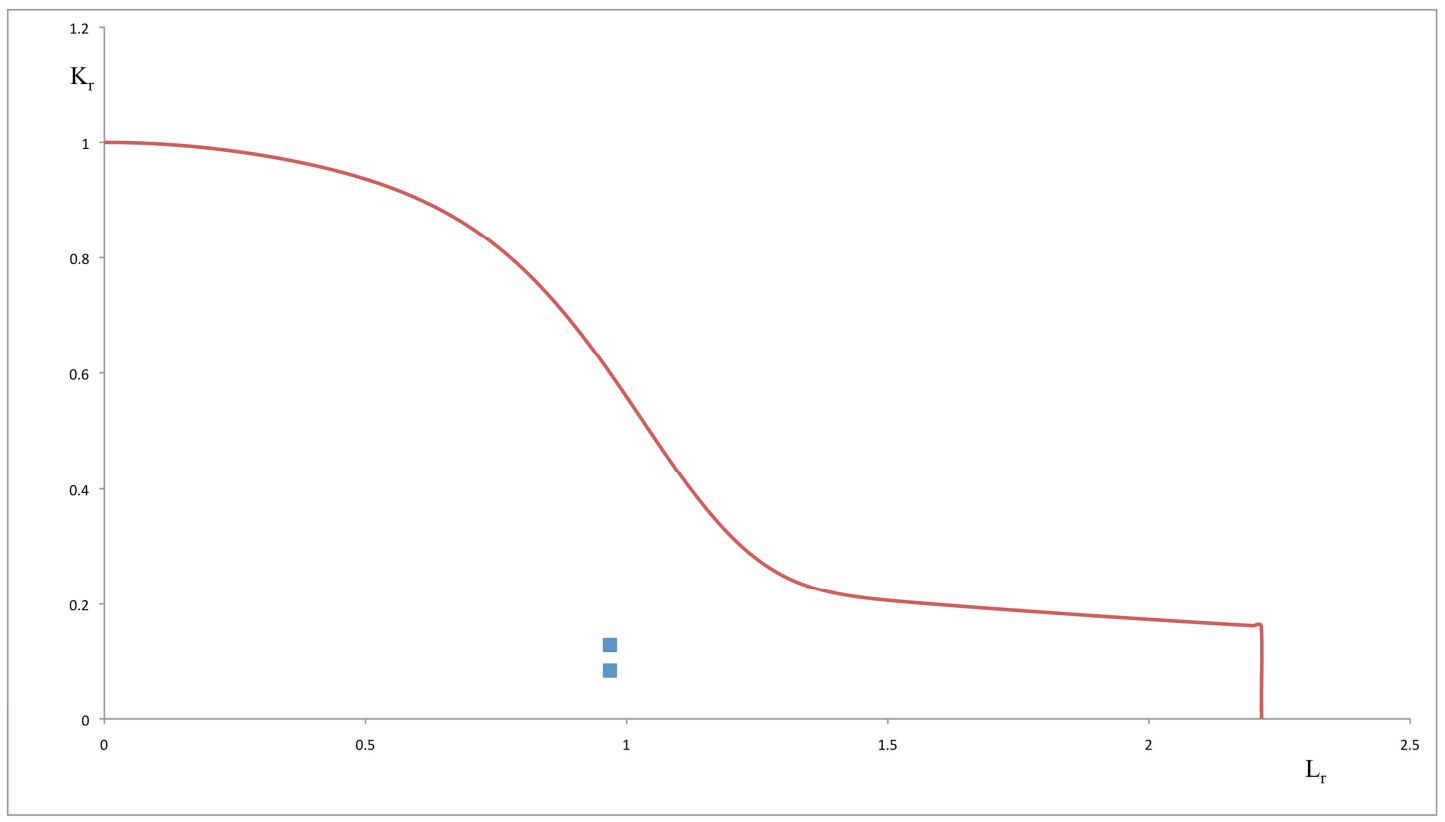

Figure 4. Assessment points for the initial flaw on the failure assessment diagram.

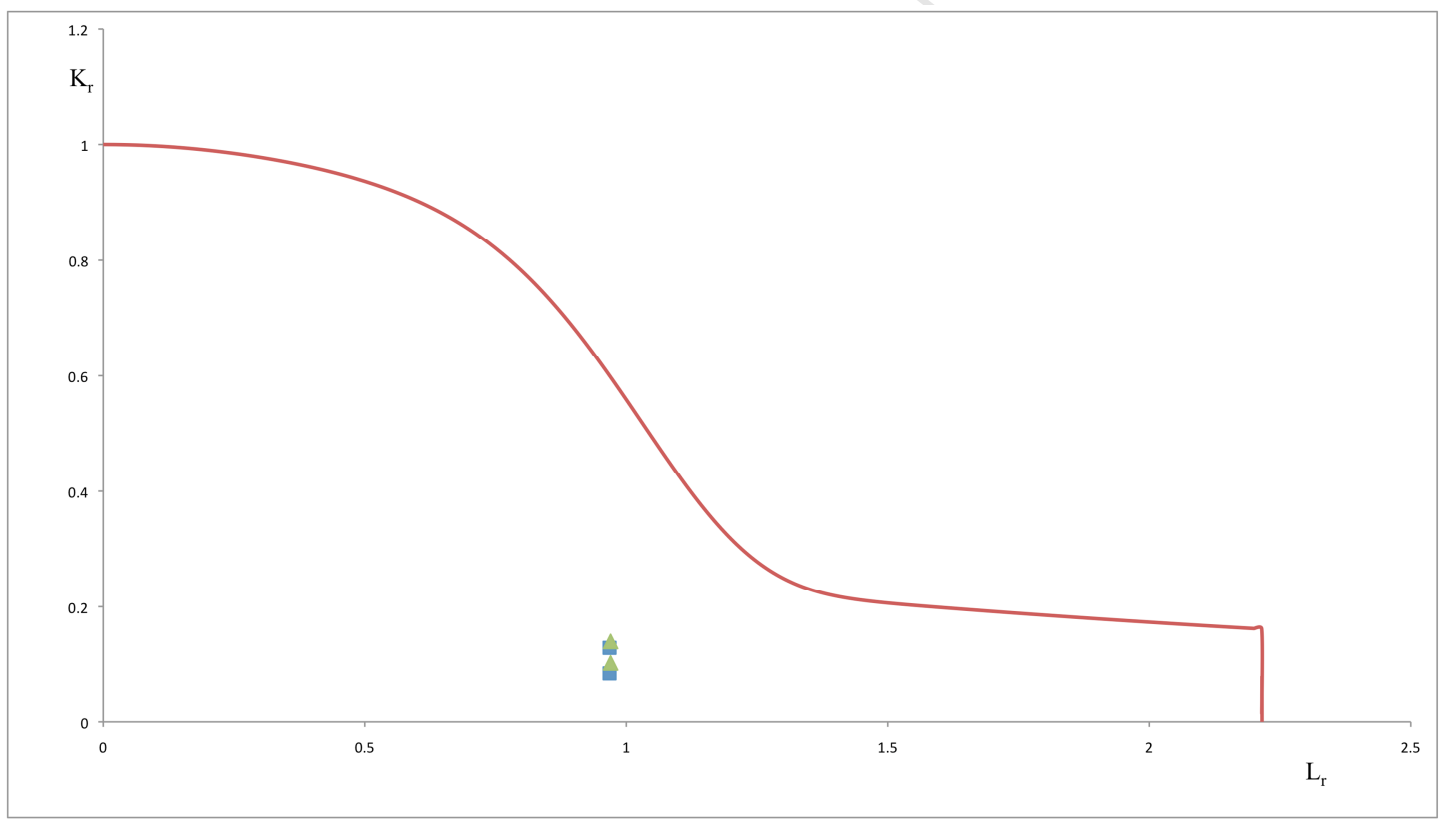

Figure 5. Assessment points for the initial and final flaw sizes on the failure assessment diagram. 